\title{
ANALYSIS OF THE CURRENT STATE OF UNSTABLE GEOMORPHOLOGICAL STRUCTURES WITH MODERN METHODS
}

\begin{abstract}
The paper gives results of the digitization of the status and spatial position of a cliff in the Western Crimea coastal zone. The modern equipment and methods accelerate the survey from the time perspective and improve the quality of the outcomes; namely a high precision GNSS receiver in RTK mode and PHANTOM-3 PRO copter. The digital terrain model was generated with used the Agisoft Photoscan software. The paper shows that the precision of the mathematical model of the relief constructed by aerial photographs provides more detailed data in comparison to those obtained in the field observations. Furthermore, aerial photography makes it possible to calculate the number of spatial characteristics of hazardous for surveying and latent natural objects out of reach for an on-location investigation. As a result, the very detailed data about current condition of dangerous cliff were obtained. The paper also evaluates the linear and volumetric characteristics of cleavages that are prone to collapse.
\end{abstract}

KEY WORDS: Crimea, coastal zone, field observations, relief modeling, photogrammetry

CITATION: Vyacheslav V. Dolotov, Yuri N. Goryachkin, Andrey V. Dolotov (2019) Analysis Of The Current State Of Unstable Geomorphological Structures With Modern Methods. Geography, Environment, Sustainability, Vol.13, No 1, p. 195-199

DOI-10.24057/2071-9388-2019-20

\section{INTRODUCTION}

The information on the sea coastal zone relief with its variability is always of particular interest in the safety of economic activities and the sustainability of nature.

The leading Russian scientists Zenkovich V. (Zenkovich 1960, Zenkovich 1962) and Longinov V. (Longinov 1963) focus on these issues in particular; a specialized terminological guidebook on the marine geomorphology (Geomorphology 1980) was published in 1980 that marked the end of the first stage of the seacoast study. Further, it served as a tool for the coastal zone dynamics studying (Shuisky 1984).

One of the most important parts of the Russian coastal zone is the Black seashores that have always been attracting people with their amazing nature. That caused the recognized Man vs. Nature Conflict that was rooted in the coastal areas reconstruction that broke the fundamental natural laws (Agarkova 1999, Ivanov, etc. 2006). At the same time, tourism and recreation as an important part of medical and social spheres are inevitably facing challenges.

At the beginning of the 21 st century, the situation started worsening on the Black Sea coasts of the Caucasus and Crimea, which initiated in-depth research both of the Caucasus (Peshkov 2003), and of Crimea (Shuysky 1974, Romanuk 1992, Goryachkin 2009). At the same time, the most severe damage was noticed in the beach areas of the coasts; and earlier attempts to strengthen the coasts with concrete structures have resulted in more dramatic damage only (Peshkov 2003, Shuysky 2005, Goryachkin 2011).

The adoption of the Crimea Supreme Council Resolution (The main .. 2004) by the municipal authorities of Crimea, as well as the scientific methods development of cadastral evaluation of the beaches recreational resources (Dolotov 2010), proved they are ready to recognize the importance of the up-to-date knowledge and methods to ensure the stability of coastal zones, and the beaches preservation in particular. The unique technique covers the exhaustive indicators of beaches and their recreational areas, taking all geomorphologic characteristics. The particular attention should be given to the state of dynamic landforms, especially unstable ones such as cliffs. The interdisciplinary study, carried by Crimea economists and rehabilitation specialists (Efremov 2003), developed the method of monetary assessment of the beaches' recreational resources, based on the evaluation of the individual recreational factors on health. This paper indicates the importance of permanent monitoring of the dynamics in coastal zones.

The great importance of the permanent monitoring of high dynamic landforms in the coastal zone was noted in the past, e.g. (Goryachkin et al. 2009; Dolotov et al. 2017-a; Udovik 2009). The natural cliff foundering, investing in the formation and recharge of beaches, causes the gradual extension of the coastal zone inland challenging the economic activity within the seashores. The significant changes in the spatial position of the coastline are mainly the result of the storms affecting extended sites of the coast.

There was a requirement to upgrade the methods and measuring equipment, and to increase the spatial positioning accuracy for any natural and artificial object as a priority, as proved in the paper.

\section{MATERIALS AND METHODS}

The former methods of the coast studying were quite primitive, though up-to-date once, with limited capacity in measuring the width of beaches and the distance between the cliff edge and some fixed ground reference points. They were quite time-consuming and therefore used to fail to pinpoint the contours of extended curved objects.

The aerial survey technologies and the gradual rise of the field survey accuracy (Kosyan 2012, Manuel 2012) ensured the significant progress in those studies. However, the current compliance of the accuracy with the uncertainty of a few meters, taking into account the spatial dimensions of 
the measured objects, requires georeferencing with the use of highly accurate GNSS devices (Pulling... 2010). The more accurate photographs are too expensive (Goryachkin et al. 2009). Thus, the monitoring of the coastal zone is only possible periodically, mainly along with approved expeditions. Given this, the analysis of a particular storm impact on the coastal landforms faces challenges, which affects the accuracy of the assessment and prognosis.

The introduction of drones as aerial survey equipment rocketed the quality of the coastal instruments. The drone advantages in the coastal zones studying are obvious. These include first of all the simplicity and cheapness in obtaining high-resolution images (Tao 2001). Drones along with the up-to-date software allow taking photographs in the photogrammetry mode in a short time, which allows you to elaborate the significantly accurate, and, what is of the most importance, - the detailed digital terrain models. The estimation of the exactness of these models (Dolotov 2017-b, Pikelj 2017, Krylenko 2018) for that case meets the requirements of the tasks. It is to be stressed that to ensure the methods assessment completeness, a significant model accuracy in terms of the spatial location of the horizontal and vertical points one can only get when georeferencing the very particular relief element in the images thus ground control points (GCP) to its real location.

However, according to the recommendations of the software developers (Unmanned... 2018) the number of these GCPs can be relatively small. Those GCPs can be assigned as temporary marks, particularly at the breakpoints of relief assessment that lacks constants, or as fixed marks at stationary elements of the terrain. Corners of retaining walls and berths and nearly any low capital constructions can serve as the stationary elements to pinpoint the location. As a result of the long-term monitoring, the staff of the Marine Hydrophysical Institute of RAS constructed an exhaustive database of landmarks with the use of the GNSS-receiver in RTK mode (Geodesy... 2018) on the sites that use by the institute, and that extends from Saky, the town in the North of Crimea, to the Tolstoy Cape in the South.

This database makes it possible to survey the area promptly with the use of a Phantom3 Pro drone equipped with a high-resolution camera. All the landmarks registered in the base go along with the images and survey points location map as well as with the fixed coordinates matching the elevation level.

\section{RESULTS}

The study focuses on the possibilities of digitization of natural objects on the base of the prone to slumping coastal area located to the North from Nikolaevka village in Western Crimea (Fig. 1).

The study site is a beach 4-20 meters wide and $1.1 \mathrm{~km}$ long, located at the foot of the nearly vertical cliff with a height of around 15 meters. Following the basic concepts of the dynamic of this geomorphological structure, the cliff would slump periodically (traces of these process are in Fig. 1, right), and at the same time, there are several natural cleavages (box in Fig. 1) at its upper part, what implies the further contribution to the beach by this source.

While traditional measuring, the upper edge coordinates of the cliff are surveyed like extra points to the beach parameters, but the measurements are to be conducted every 2-5 $\mathrm{m}$ along the edge, i.e. from 200 to 500 measurements, to ensure the pinpointing of its contour. There were 48 measurements only taken, however, throughout the real survey of the cliff, i.e. about 5-10 times less than assumed.

There were two drone flights within the survey based on the above-mentioned approach from the center to both sides, traversing twice, taking 87 images with overlapping $60 \%$ along the direction of the flight, as well as across (Fig. 2). The flights were performed at $80 \mathrm{~m}$ altitude from the cliff level at a speed of $3.5 \mathrm{~m} / \mathrm{s}$. By the speed increase up to $4 \mathrm{~m} / \mathrm{s}$, there were occasional omissions seen in a set of images, and therefore the speed of $3.0-3.5 \mathrm{~m} / \mathrm{s}$ was considered optimal. The flight routes were developed by the Basic version of the Drone Harmony program (Professional... 2018).

The images were processed by the trial version of Agisoft Photoscan (Unmanned... 2018). After the images uploading, they were spatially aligned with 16 GCP, six out of them located on the plane of the beach, eight at the height of the upper limit of the cliff and two on the concrete staircase leading to the sea in the southern part of the beach. The model with the following characteristics was elaborated as a result of the survey (Fig. 3):
- images: 87;
- GCP: 16;
- tie points: 94625;
- dense cloud of 53654822 points;
- model of 10604753 polygons.

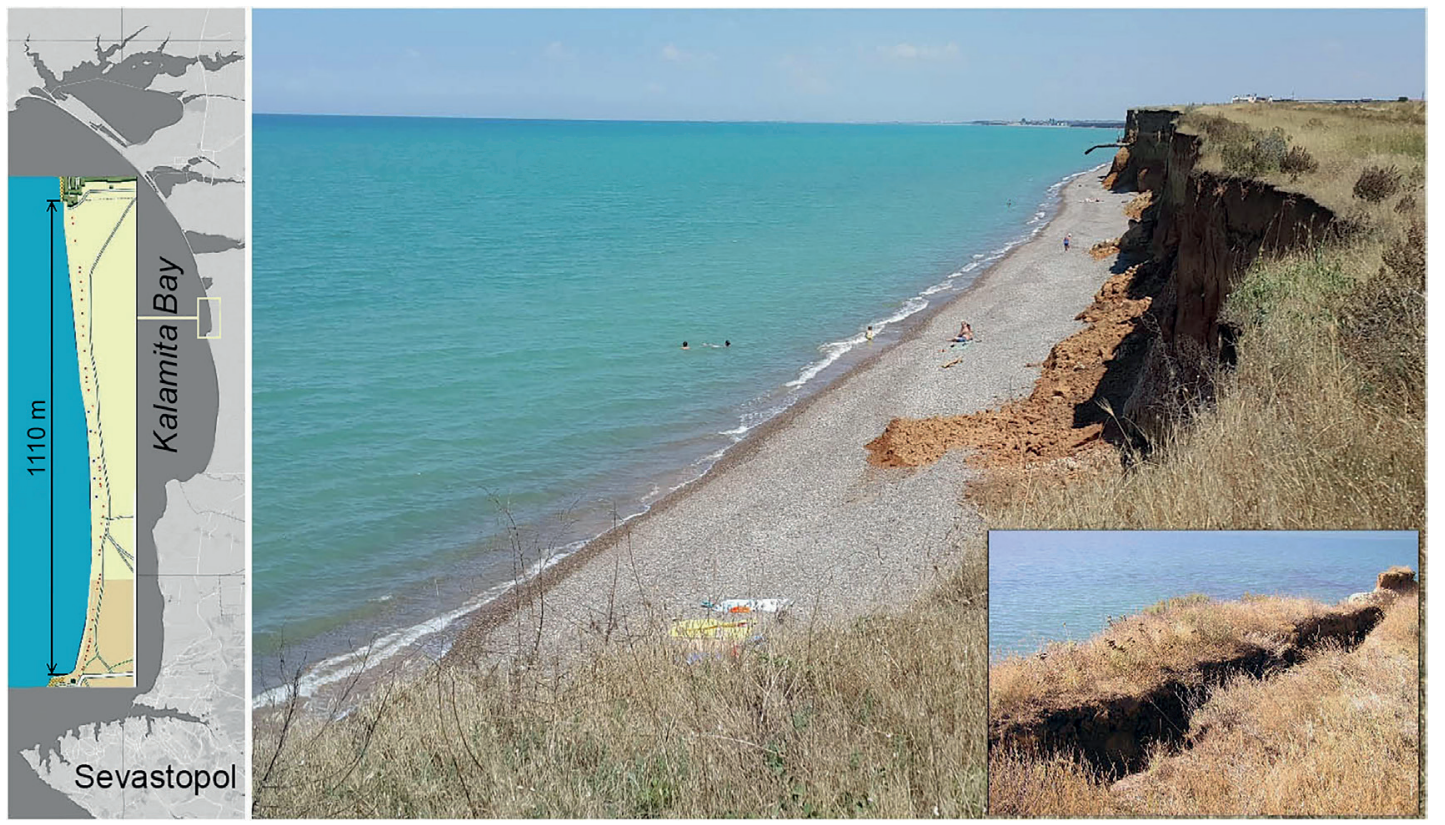

Fig. 1. The coast near the Nikolaevka village; one of the sites with a typical cleavage (box) 

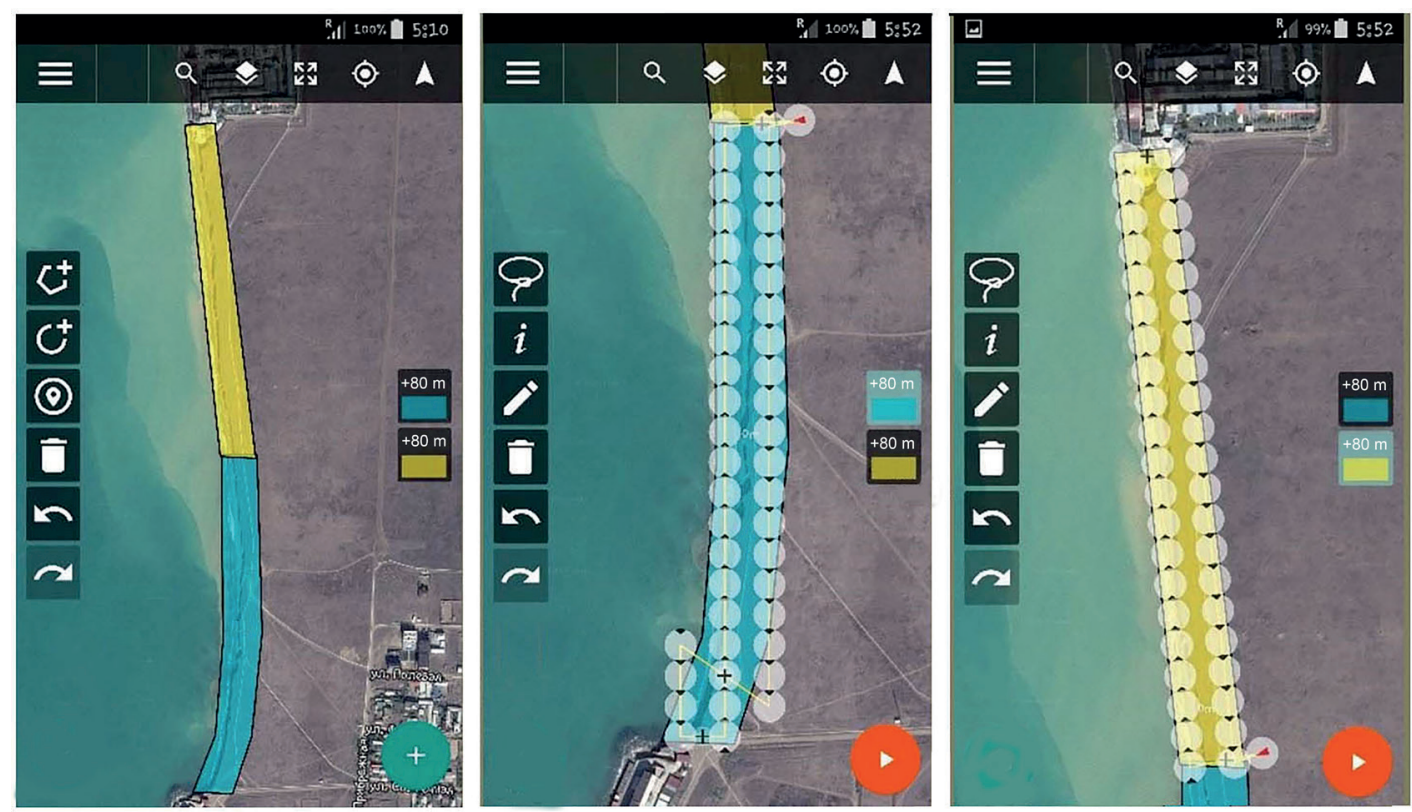

Fig. 2. Flight plan (left) and image locations taken by each drone (center, right)
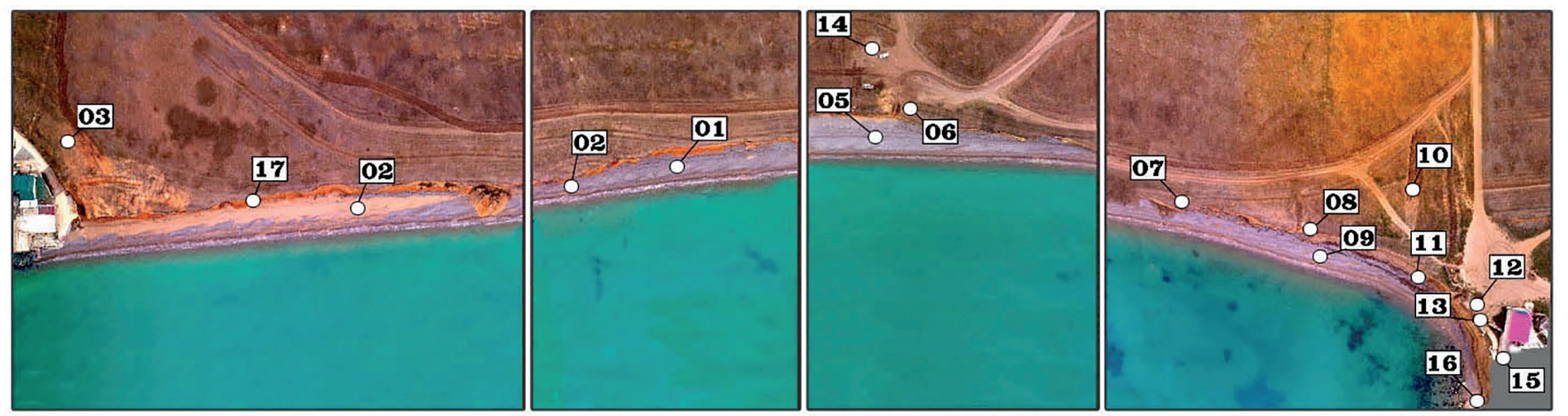

Fig. 3. Visualization of the model with the use of an image texture

The height map of size $6508 \times 35504$ pix with a resolution of $4.88 \mathrm{~cm} /$ pix and the orthophotomap of size $8412 \times 49350$ pix with a resolution of $2.44 \mathrm{~cm} /$ pix were elaborated based upon the received data.

The digitizing of the cliff edge was also carried out with the use of the traditional drawing procedure of the polyline from the top look. For the case when the point fell to the flat of a beach, its position was corrected shoreward and controlled in the vertical direction by switching to the front look. There were 468 points along the edge of the cliff digitized totally with a mean distance of $2.3 \mathrm{~m}$. Forty-seven points extra were obtained by a GNSS-receiver (Fig. 4), and the corresponding points coincided.

It is clear that for the case of a crooked survey area the distance between the points tends to be reduced to $1 \mathrm{~m}$ or less (Fig. 5) and if necessary, the total quantity of digitized points can be significantly increased.
The extra evaluation of some linear and volumetric characteristics of cleavages, which did not lie in the horizontal flat in contrast to the edge of the cliff, seemed interesting throughout the survey. These characteristics cannot be measured within on-location measurements. Eight explored cleavages were digitized in the same way, i.e. by drawing a line along the contour of the segment that split from the landmass (Fig. 6).

Thus, on the presented model, the length of the line within horizontal points was $7.4 \mathrm{~m}$ long, and the total volume of the landmass within the extreme points was $18.4 \mathrm{~m}^{3}$. It is interesting to note that this model allows building and displaying the vertical section constructed by digitized points (box in Fig. 6) as well, which shows that many of digitized points initially hid in the cleavage. This result confirms that to perform accurate measurements of the geometric dimensions of objects it is necessary to perform pre-alignment of digitized points in the vertical flat.

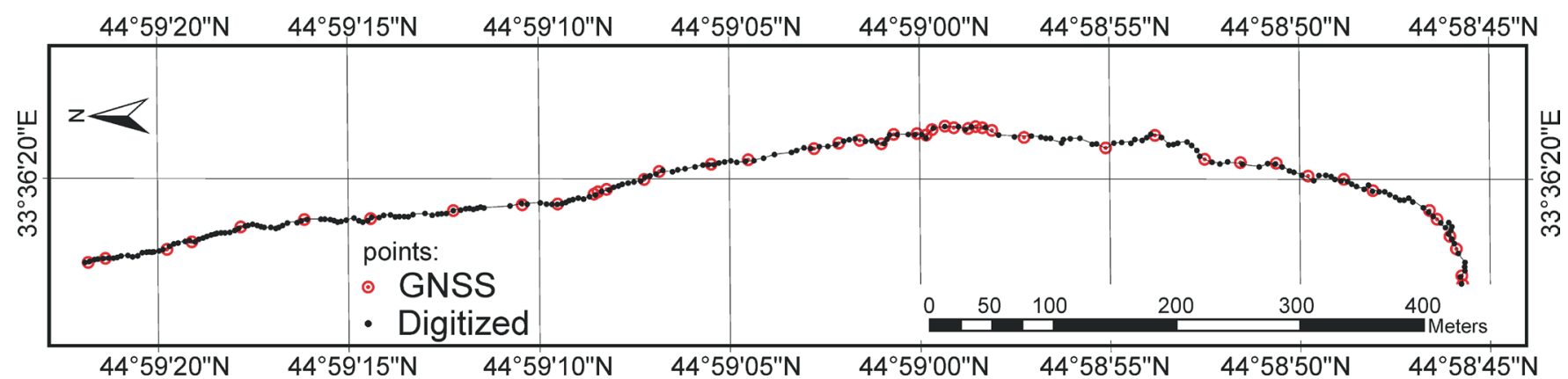

Fig. 4. Spatial position of points throughout the survey 


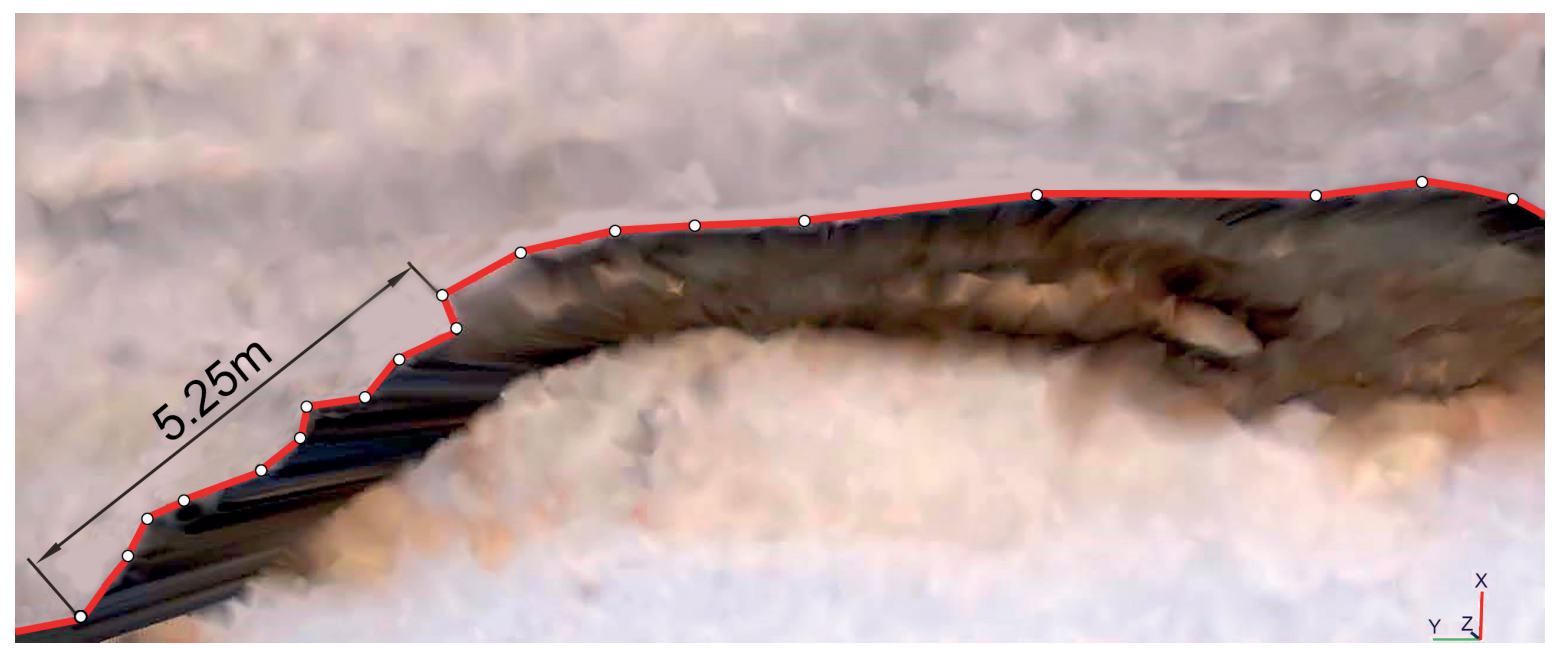

Fig. 5. The site of the cliff edge digitized by means of Photoscan

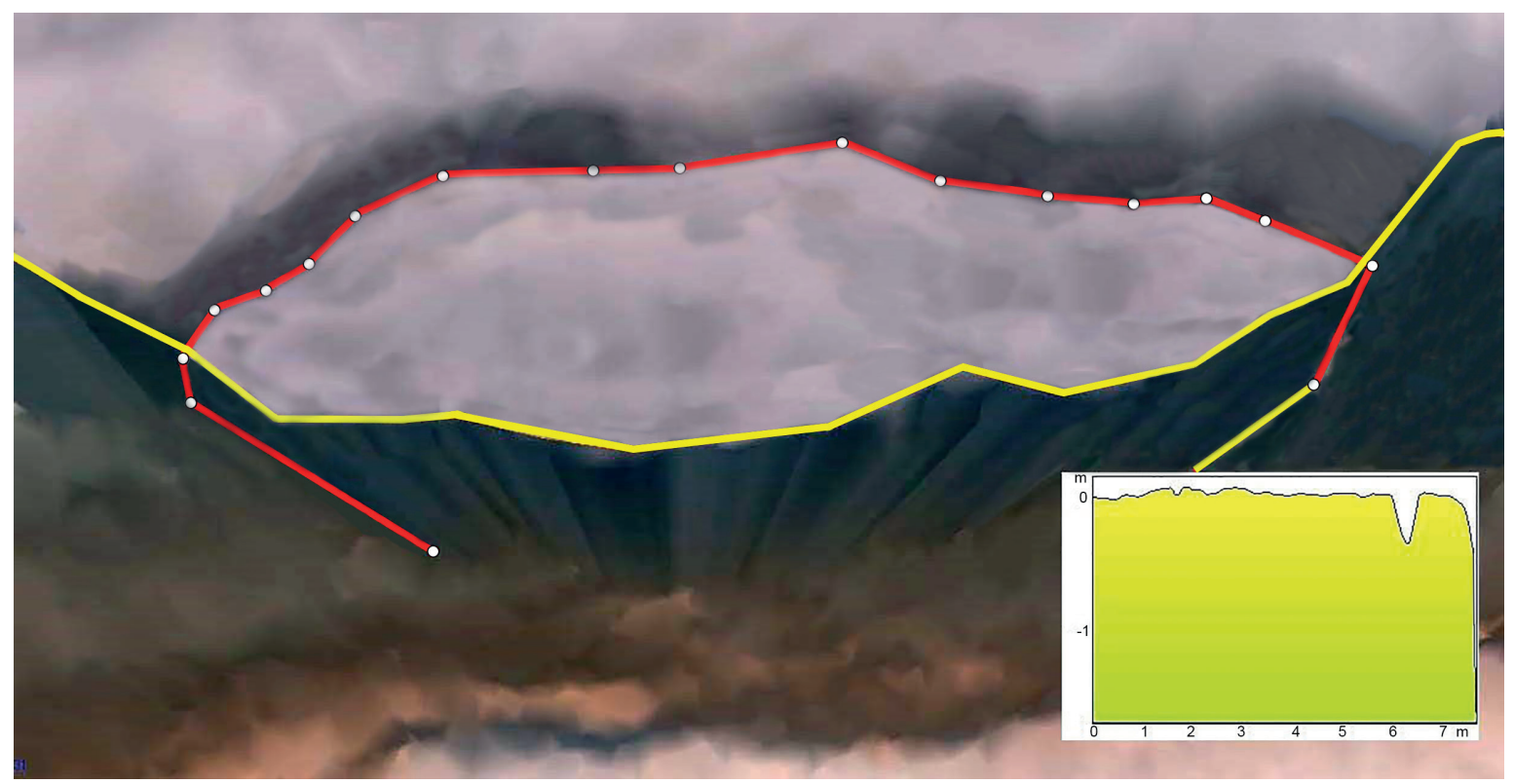

Fig. 6. The digitization of cleavage with a polyline

\section{DISCUSSION}

The results show that the modern survey technologies provide significant progress in the determining of the spatial position of individual geomorphological structures, including those inaccessible to on-location measurement. The main advantages of the method are the speed of taking photographs resulting in the high-precision digitization and measurements of the spatial position of individual natural objects, including those that cannot be measured in on-location surveys. The results of the omitting in this paper video-filming also allow us to estimate the thickness of the upper gravel layer, which together with the results of measuring the volume of existing natural cleavages allows quantifying the amount of landmass expected to recharge the beach in the near future.

\section{CONCLUSIONS}

No question that the most significant results of the survey are expected to be later in further monitoring of the coastal zone in Western Crimea. At present, according to the results of long-term observations of two sites accomplished by the authors, the beach extension from 2004 to 2014 was estimated to be $1.6 \mathrm{~m}$ with a mean rate of $0.14 \mathrm{~m} / \mathrm{yr}$. In this regard, the obtained results make it possible to assess the coast retreat in some areas with high accuracy. This allows early identification of both dangerous and dynamic areas of the coast to make proper decisions on its protection. At present, the results are the first detailed data array on the spatial position of the cliff edge facilitating the identification and estimation of the potential slump in the study site of the coast.

\section{ACKNOWLEDGEMENTS}

The present study was undertaken within «Complex Interdisciplinary Studies of Oceanological Processes that Determine the Functioning and Evolution of the Black and Azov Seas Ecosystems Based on Modern Methods of Monitoring the Marine Environment and Grid Technologies» State Task №0827-2014-0010, and RFFI project №18-45-920021 (2018). 


\section{REFERENCES}

Agarkova I.V. (1999). Influence of economic activity on the dynamics of the Saki coast. Scientific notes of Vernadsky Taurida National University, 12, Simferopol, 15-19 (in Russian).

Dolotov V.V, Ivanov V.A. (2010). Cadastral Assessment of Crimean Beaches as an Instrument for Sustainable Coastal Development. GEOGRAPHY, ENVIRONMENT, SUSTAINABILITY, 3(2), 98-119.

Dolotov V.V., Goryachkin Yu.N., Dolotov A.V. (2017-a). Statistical analysis of changes in the shoreline of the village Lyubimovka beach. Environmental safety of coastal and shelf zones and integrated use of shelf resources, 1, 40-47. (in Russian with English summary).

Dolotov V.V., Udovik V.F. (2017-b). Use of innovative technologies for monitoring the coastal zone of Crimea, Environmental safety of coastal and shelf zones and integrated use of shelf resources, 4, 67-77. (in Russian with English summary).

Efremov A.V. (2003). Considerations for the beache's economic evaluation. Crimea Economics, 6, 57-60 (in Russian).

Geodesy with pleasure. (2018). Effective technology. [online] Available at: www.eftgroup.ru [Accessed 28 Marth 2019].

Goryachkin Yu.N., Kharitonova L.V., Dolotov V.V. (2009). North-Western Crimea coastline variability. Environmental safety of coastal and shelf zones and integrated use of shelf resources, 20, 18-26 (in Russian).

Goryachkin Yu.N., Dolotov V.V. (2011). Changes in the shoreline of the accumulative shores of Western Crimea. Environmental safety of coastal and shelf zones and integrated use of shelf resources, 25, 8-18 (in Russian).

Goryachkin Yu.N. (2015). The current state of the coastal zone of Crimea. Sevastopol: ECOSI-Gidrophysics (in Russian).

Ivanov V.A. Yastreb V.P., Goryachkin Yu.N., Prusov A.V., Zima V.V., Fomin V.V. (2006). Nature management on the black sea coast of Western Crimea: current state and development prospects, Sevastopol: MHI (in Russian).

Kosyan R.D., Goryachkin Yu.N., Krylenko V.V., Dolotov V.V., Krylenko M.V., Godin E.A. (2012). Crimea and Caucasus accumulative coasts dynamics estimation with using satellite pictures. Turkish Journal of Fisheries and Aquatic Sciences. 12, 385-390.

Geomorphology of sea shores (1980). Ed. Zenkovich V.P. Moscow: Mysl (in Russian).

Krylenko V.V., Krylenko M.V. (2018). High-precision topography bakalskaya spit. Environmental safety of coastal and shelf zones, 4, 65-72 (in Russian with English summary).

Longinov V.V. (1963). Dynamics of the non-tidal seas coastal zone. Moscow: Academy of Science (in Russian).

Manuel A. Aguilar, Fernando J. Aguilar, María del Mar Saldaña and Ismael Fernández (2012). Geopositioning accuracy assessment of GeoEye-1 panchromatic and multispectral imagery. Photogrammetric Engineering \& Remote Sensing, 78, 3, 247-257.

Peshkov V.M. (2003). Coastal zone of the sea. Krasnodar: Lacont (in Russian).

Pikelj K. (2017). Ocean and Coastal Management. DOI: 10.1016/j.ocecoaman.2017.11.019 [Accessed 16 May 2018].

Professional flight planner for DJI Drones (2018). DH DRONE HARMONY. [online] Available at: www.droneharmony.com [Accessed 16 May 2018].

Pulling in All Signals. (2010). PPP with GPS and GLONASS: The New G2. GPS World, 3, 28-36.

Romanuk O.S., Lushik A.V., Morozov V.I. (1992). Conditions of formation and dynamics of the sea coast in the area of Saki resort zone, Simferopol: IMR, 12-21 (in Russian).

Shuisky Yu.D. (1974). Processes and rates of abrasion on the Ukrainian shores of the Black and Azov seas. News of USSR Academy of Sciences. ser. Geography, 6, Moscow, 107-117 (in Russian).

Shuisky Yu.D., Vykhovanetz G.V., Karasev L.M., Makeev I.A. (1984). Morphology and dynamics of the coast of the South-Western part of the Crimean Peninsula. Physical Geography and Geomorphology, 31, $83-88$ (in Russian).

Shuisky Yu.D. (2005). The main regularities of morphology and dynamics of the West coast of the Crimean Peninsula. Environmental safety of coastal and shelf zones and integrated use of shelf resources, 13, $62-72$ (in Russian).

Tao, C.V. and Y. Hu (2001). A comprehensive study of the rational function model for photogrammetric processing. Photogrammetric Engineering \& Remote Sensing, 67(12), 1347-1357.

The main directions of development of sanatorium-resort and tourist (recreational) complex of the Crimea until 2010. (2004). Resolution of the Supreme Council of Crimea, March 17(849-3/04).

Udovik V.F., Dolotov V.V. (2009). Modern trends in the dynamics of the coastal zone in the area of the beach village Lyubimovka. Environmental safety of coastal and shelf zones and integrated use of shelf resources, 20, 92-99. (in Russian).

Unmanned technologies for professionals (2018). GEOSCAN'S Official Website. [online] Available at: www.geoscan.aero/ [Accessed 16 May 2018].

Zenkovich V.P. (1960). Morphology and dynamics of the Soviet black sea coast. Moscow: Academy of Science. (in Russian).

Zenkovich V.P. (1962). Fundamentals of the development of sea shores doctrine. Moscow: Academy of Science (in Russian). 